\title{
Brushless DC Motor Drive and Control circuit Simulation and FPGA implementation
}

\author{
Priti Pujara \\ G. H. Patel College of Engineering \& Technology \\ Vallabh Vidyanagar, Gujarat
}

\author{
Jatin Patel \\ G. H. Patel College of Engineering \& Technology \\ Vallabh Vidyanagar, Gujarat
}

\begin{abstract}
Brushless DC motor is permanent magnet synchronous motor with trapezoidal back EMF. Brushless DC motor replaces conventional brushed motors due to its advantages like higher efficiency. In this paper, BLDC drive circuit and control is simulated. A highly efficient second order Butterworth passive filter is designed and implemented. Digital control of BLDC motor using pulse width modulation of $50 \mathrm{KHz}$ PWM switching frequency is implemented in Field Programmable Gate Array. Maxon EC 60W motor is used for hardware implementation and testing. This paper discusses various implementation aspects related to BLDC motor drive and control circuit.
\end{abstract}

\section{Keywords}

Brushless DC motor, FPGA, PWM, Control, Drive Circuit, Passive Filter, MATLAB/ SIMULINK

\section{INTRODUCTION}

Brushless DC motor is synchronous motor with trapezoidal back EMF. It is called 'DC' motor as its phase voltage equations are identical to the armature voltage equation of DC motor. Because of absence of brushes, it has less mechanical wear, higher efficiency, longer operating life and noise less operation. Compared to conventional motors it has better speed versus torque characteristics, faster dynamic response and high torque to size ratio [1].

BLDC motor needs electronic commutation, in which based on rotor position drive circuit energize stator winding. Thus BLDC demands position sensing. Rotor position can be known by using various sensors like hall sensor. Hall Effect sensors are embedded on motor stator works on Hall Effect; giving 3 - bit code for $120^{\circ}$ separated three hall sensors.

To drive BLDC motor based on rotor position, various drive circuits are available. Six step three phase inverter is simpler and gives symmetric output voltage but its disadvantage is more number of switches and so freewheeling diode. Four switch Three phase Voltage source inverter offers reduced number of switches but has decreased voltage gain, large voltage variation across capacitors, asymmetric voltage [2], [3]. Boost four switch three phase voltage source inverter and current source inverter are proposed in [4] and [5] respectively.

\section{ELECTRONIC COMMUTATION}

Brushless DC motor is not self-commutating, hall sensors and drive circuit play role of mechanical commutator and brushes. Hall sensor gives rotor position and controller controls switching of MOSFETs in drive circuit as per rotor position. Table 1 shows electronic commutation sequence for clock wise rotation when seen from shaft end. Hall sensor signals are 3- bit code formed by Hall sensor A, Hall sensor B and
Hall sensor $\mathrm{C}$, while $\mathrm{AH}, \mathrm{BH}, \mathrm{CH}$ are upper MOSFETs and $\mathrm{AL}, \mathrm{BL}, \mathrm{CL}$ are lower MOSFETs in three phase inverter circuit.

TABLE I. Commutation Sequence (Clock Wise Rotation)

\begin{tabular}{|l|l|l|l|l|l|l|l|}
\hline $\begin{array}{l}\text { Rotor } \\
\text { Position } \\
\text { (Degrees) }\end{array}$ & $\begin{array}{l}\text { Hall } \\
\text { sensor } \\
\text { Signal }\end{array}$ & AH & BH & CH & AL & BL & CL \\
\hline $0-60$ & 101 & 1 & 0 & 0 & 0 & 1 & 0 \\
\hline $60-120$ & 100 & 1 & 0 & 0 & 0 & 0 & 1 \\
\hline $120-180$ & 110 & 0 & 1 & 0 & 0 & 0 & 1 \\
\hline $180-240$ & 010 & 0 & 1 & 0 & 1 & 0 & 0 \\
\hline $240-300$ & 011 & 0 & 0 & 1 & 1 & 0 & 0 \\
\hline $300-360$ & 001 & 0 & 0 & 1 & 0 & 1 & 0 \\
\hline
\end{tabular}

The commutation sequence is applied with pulse width modulation for control. In that case, the waveform for above commutation sequence is as shown in Figure 1. Soft chopping is used (Only lower MOSFETs are applied with PWM) for less switching losses.

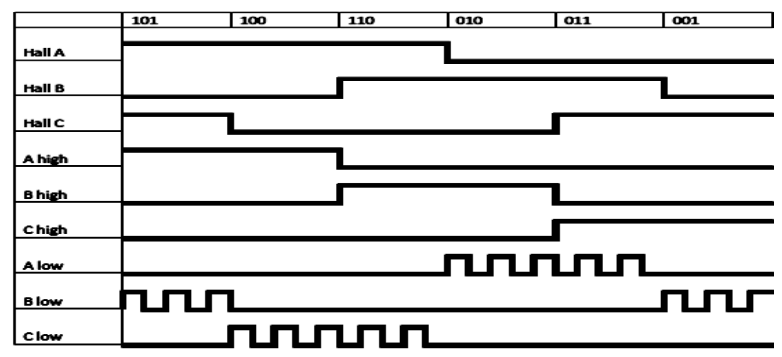

Figure 1. Switching pulses with respect to Hall sensor signal (Soft Chopping)

Drive circuit is as shown in Figure 2. Three phase inverter formed by all $\mathrm{N}$-channel MOSFETs needs gate driver circuitry as Microcontrollers/ FPGA cannot supply higher current needed for charging and discharging MOSFET capacitance. Gate drive circuit provides high source and sink currents and boot strapping to upper side MOSFETs.

To control voltage supplied to motor inverter Pulse width modulation is used as shown in Figure 1. Pulse width modulated voltage generated by chopping inverter switching contains ripples that should be eliminated before applying to motor. Current is filtered due to inductance of motor coil. Low pass passive filter reduces ripples in voltage. As PWM frequency increases, filter size decreases, but higher switching losses. As a thumb rule, PWM frequency should be at least 5 to 7 times higher than cut- off frequency provided by motor time constant [6]. 


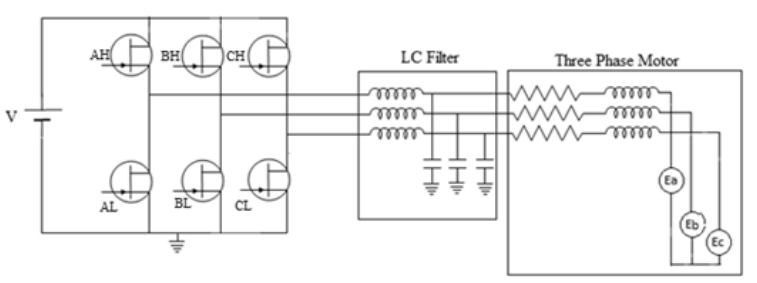

Figure 2. Three phase inverter with Motor load

To observe current in circuit, resistor is used to convert current to voltage. This voltage is given to Analog to Digital converter. ADC is interfaced with FPGA by implementing Master SPI in FPGA.

\section{DRIVE CIRCUIT SIMULATION}

\subsection{MATLAB/ SIMULINK Modeling}

To understand transient behavior of circuit, mathematical model of Brushless DC motor is developed using MATLAB/ SIMULINK [7][8]. Torque $\left(\mathrm{T}_{\mathrm{e}}\right)$ is proportional to current. Current is very high at starting due to zero back EMF and as it reaches to steady state current reduces. Speed can be obtained from torque, and rotor position $\Theta$ from speed.

$I_{x}=\frac{V-E}{R}$

$T_{e}=K t\left(I_{a}+I_{b}+I_{c}\right)=J \frac{d \omega}{d t}+T_{L}+B \omega_{r}$

Thus,

$$
\omega_{r}=\frac{1}{J} \int T_{e}-T_{L}-B \quad \theta_{m}=\int \omega_{r} d t(3)
$$

These equations are modeled in SIMULINK/ MATLAB to model Brushless DC motor. This model was used to observe transient condition and PID control was implemented.

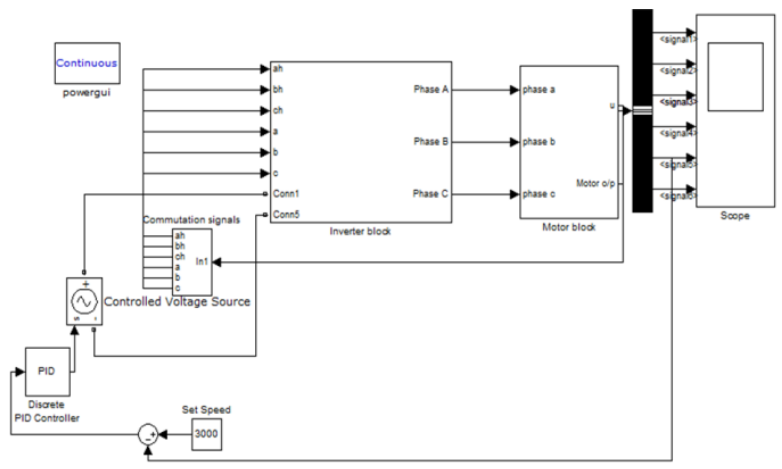

Figure 3. MATLAB/ SIMULINK Model

Detailed Motor block is as shown in Figure 4. Back EMF and hall sensor block is having MATLAB functions which is having output based on rotor positon.

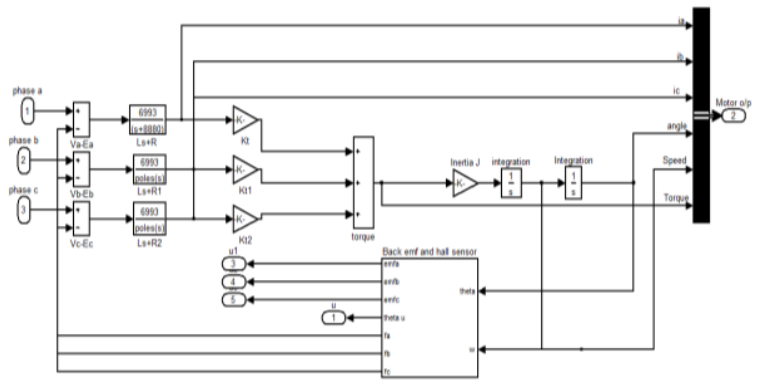

Figure 4. Mathematical Modeling (Detailed Motor Block)

Simulation results are taken for transient conditions of motor torque and speed as shown in Figure 5.
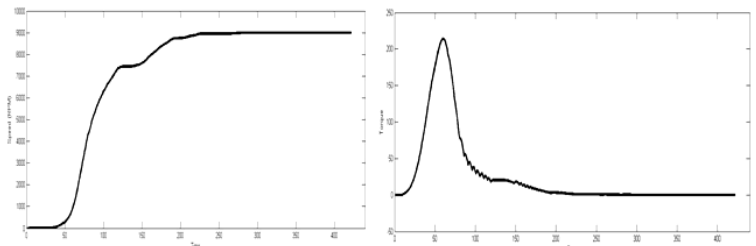

Figure 5. Starting speed and stall torque of motor (Transient Behavior)

Simulation results for close loop speed control using PI is shown in Figure 6. In that, Load torque of $100 \mathrm{mNm}$ is added at $0.1 \mathrm{~s}$ time and PI takes care of maintaining speed for step change in load torque. Back EMF waveforms are as shown in Figure 7.

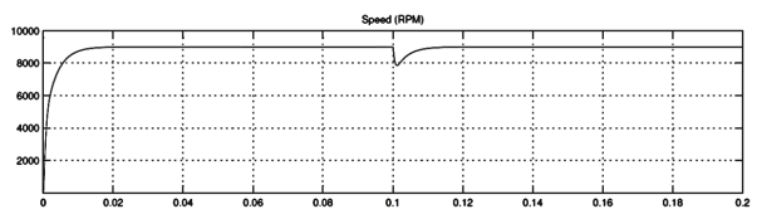

Figure 6. Set Speed $=9000$ RPM, $T_{L}=100 \mathrm{mNm}$ at $0.1 \mathrm{~s}$

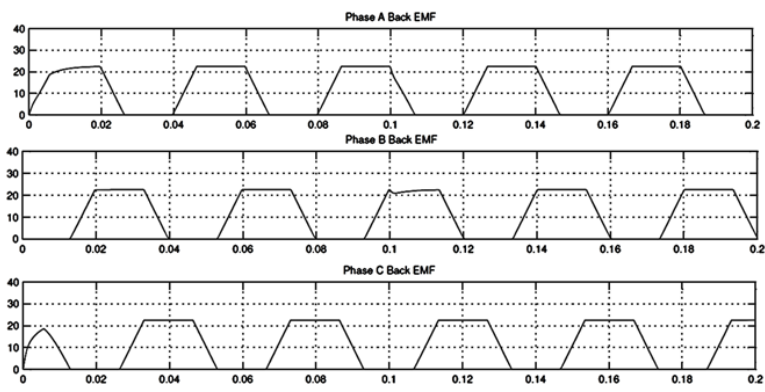

Figure 7. Back EMF of Each Phase

\subsection{PSpice Simulation}

Drive circuit is simulated in PSpice with Motor load simulated as a resistor, inductor and trapezoidal back EMF. LC filter is designed as per Butterworth polynomial to get maximally flat response in pass band. Filter $3-\mathrm{dB}$ frequency is set at $5.67 \mathrm{KHz}$. LC filter also helps in removing commutation ripples in Back EMF and Current waveforms. 


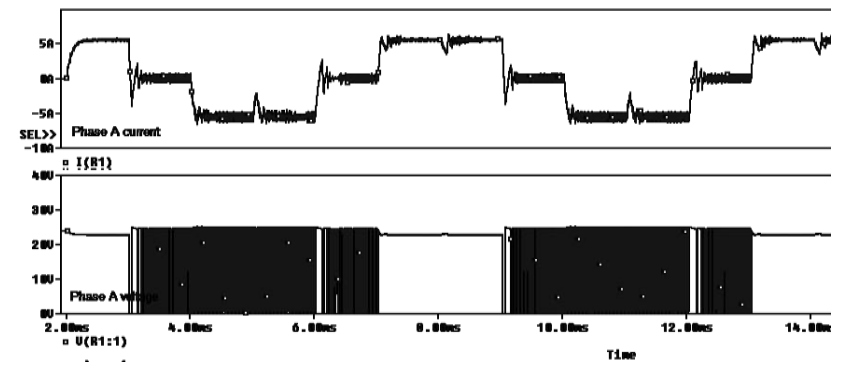

Figure 8. Current and voltage waveform without LC filter

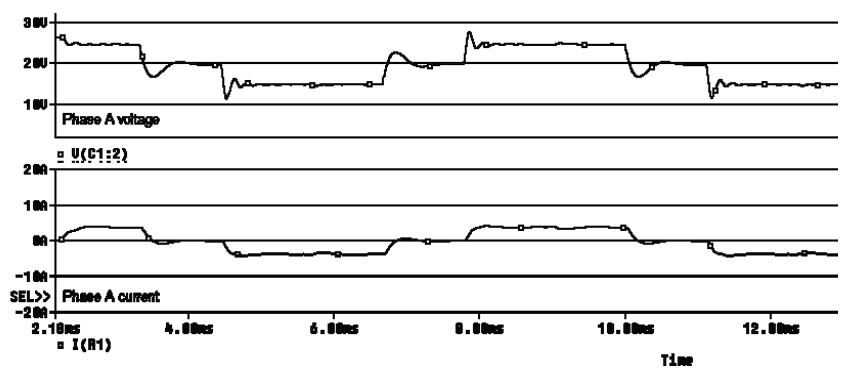

Figure 9. Voltage and current waveform with LC filter

LC filter is designed as per Butterworth polynomial to get maximally flat response in pass band. Filter $3-\mathrm{dB}$ frequency is set at $5.67 \mathrm{KHz}$. LC filter also helps in removing commutation ripples in Back EMF and Current waveforms.

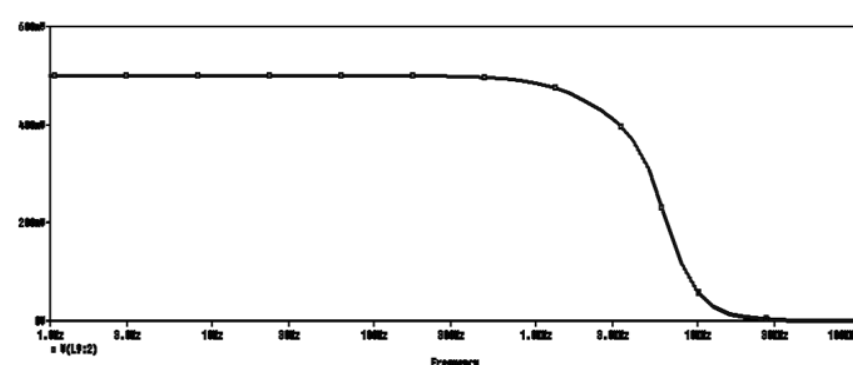

Figure 10. LC filter AC sweep response

\section{BRUSHLESS DC MOTOR CONTROL}

To control motor's speed, voltage to motor should be controlled. Open loop control does not use feedback and is used when load is steady. Digital control can be achieved using pulse width modulation. In this paper, Pulse width modulated signals are generated using counter compare method in FPGA. An 8-Bit free running counter is compared with 8- bit reference value. Here, 8- Bit counter is selected based on $10 \mathrm{MHz}$ as master clock frequency and $50 \mathrm{KHz}$ as switching frequency. Field Programmable Gate Array offers higher processing speed due to parallel execution unlike microcontrollers which executes instructions sequentially. LabVIEW GUI is developed to control duty cycle of PWM to achieve open loop control.

TABLE II. MOTOR SPECIFICATION

\begin{tabular}{|c|c|}
\hline \multicolumn{2}{|c|}{ Motor Specifications } \\
\hline Motor voltage & $24 \mathrm{~V}$ \\
\hline Rated power & $60 \mathrm{~W}$ \\
\hline Electrical time constant & $0.1 \mathrm{~ms}$ \\
\hline Torque constant & $24.3 \mathrm{~m} \mathrm{Nm}$ \\
\hline
\end{tabular}

\begin{tabular}{|c|c|}
\hline Phase resistance & $0.635 \Omega$ \\
\hline Phase inductance & $71.5 \mu \mathrm{H}$ \\
\hline Speed Constant & $393 \mathrm{~m} / \mathrm{V}$ \\
\hline
\end{tabular}

\subsection{VHDL Simulation}

VHDL code for hall sensor decoding and Pulse width modulation is created using Actel Libero.

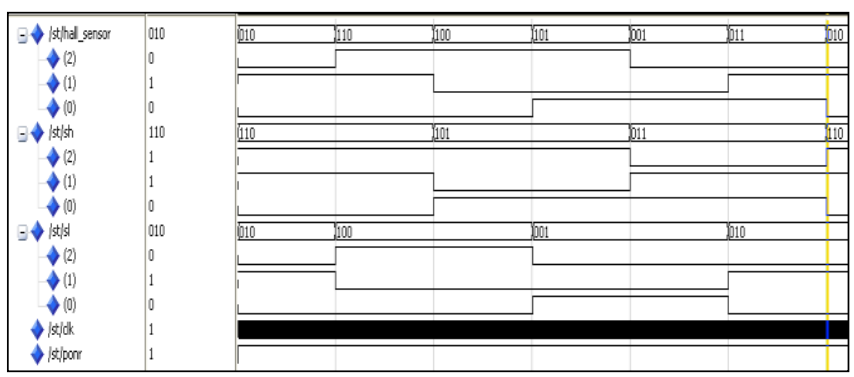

Figure 11. Hall sensor decoding logic (Post-layout simulation)

For open loop control, rising edge of FPGA input pin used to increase duty cycle. LabVIEW GUI provides rising edge of duty cycle.

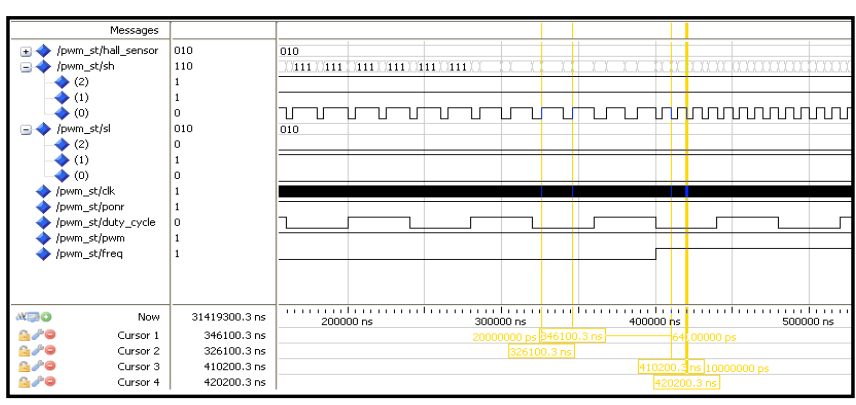

Figure 12. Variable Duty cycle and frequency (Postlayout simulation)

\section{HARDWARE IMPLEMENTATION}

Brushless DC motor drive circuit is verified and open loop control is achieved. In that changing duty cycle of voltage changes motor RPM.

Figure 13 shows voltage and current waveforms with PWM frequency of $50 \mathrm{KHz}$ and without LC filter. Figure 14 shows effect of filtering in voltage and current waveforms. These waveforms are identical to simulation results obtained.

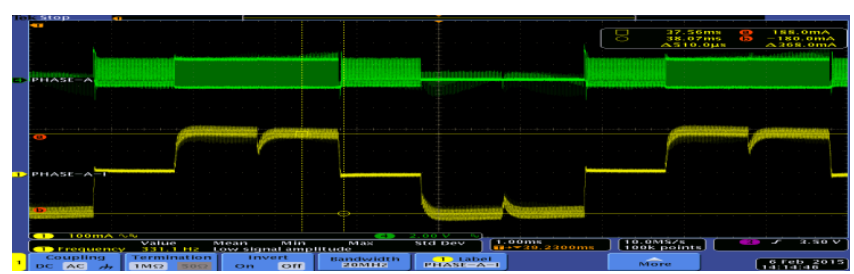

Figure 13. Voltage and Current waveform without LC filter 


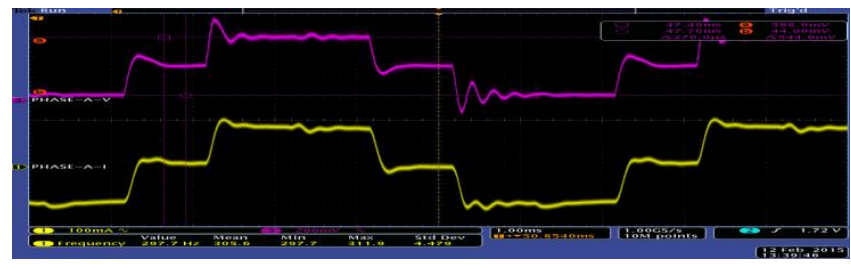

Figure 14. Voltage and Current waveform with $\mathrm{LC}$ filter

Current in circuit is monitored online using LabVIEW. DClink current is measured using resistor and ADC is interfaced with FPGA using SPI clocks. Hardware implementation of the same is shown in Fig. 15. After Chip selection signal $C S$ goes low, $S C L K$ of $1 \mathrm{MHz}$ is given to ADC chip. DIN is data input to ADC which is used to select channel of ADC. Channel 1 is selected here. 12- Bit data is acquired serially at falling edge of SCLK. Figure 16 shows data from ADC acquired in LabVIEW using NI-DAQ card.

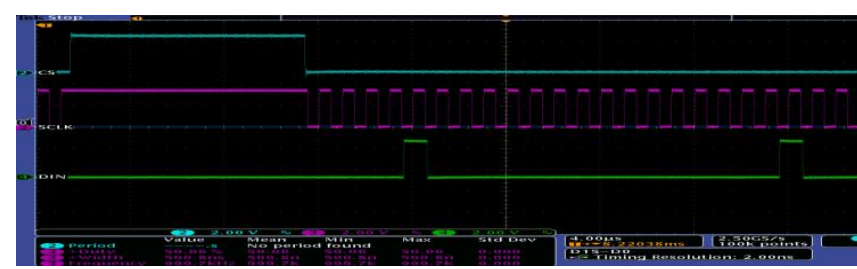

Figure 15. ADC Serial Peripheral interfacing

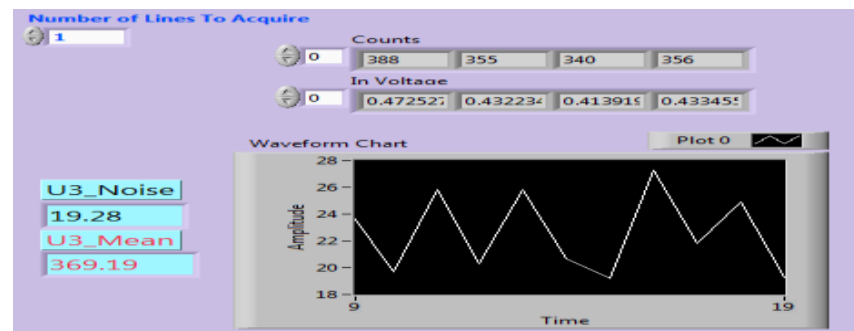

Figure 16. ADC data acquired in LabVIEW

Figure 17 shows motor speed in Rotation per Minute versus Duty Cycle graph obtained for $50 \mathrm{KHz}$ switching frequency.

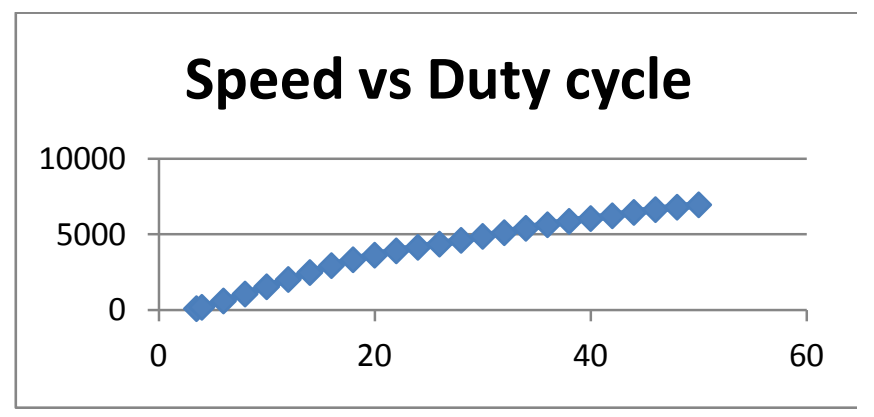

Figure 17. Motor RPM versus Duty cycle Graph

\section{CONCLUSION}

In this paper, Brushless DC motor open loop control using Field Programmable Gate Array is implemented. Hall sensor decoding logic is implemented and Pulse width modulation is incorporated for digital control. To remove PWM frequency components from voltage waveform passive Butterworth LC filter is designed. BLDC motor drive and control circuits for close loop control can be implemented by just modifying FPGA program.

\section{REFERENCES}

[1] Anand Sathyan, Nikola Milivojevic, Young-Joo Lee, Mahesh Krishnamurthy , and Ali Emadi, "An FPGABased Novel Digital PWM Control Scheme for BLDC Motor Drives" IEEE TRANS. ON IND. ELECTRON., VOL. 56, NO. 8, pp. 3040- 3049, Aug 2009

[2] Frede Blaabjerg, Dorin O. Neacsu, John K. Pedersen, "Adaptive SVM to Compensate DC-Link Voltage Ripple for Four-Switch Three-Phase Voltage-Source Inverters", IEEE TRANS. ON POWER ELECTRON., VOL. 14, NO. 4, pp. 743-752, Jul. 1999

[3] Byoung-Kuk Lee, Tae-Hyung Kim and Mehrdad Ehsani, "On the Feasibility of Four-Switch Three-Phase BLDC Motor Drives for Low Cost Commercial Applications: Topology and Control", IEEE TRANSACTIONS ON POWER ELECTRON., VOL. 18, NO. 1, Jan. 2003

[4] Changliang Xia, Youwen Xiao, Tingna Shi, and Wei Chen, "Boost three-effective-vector current control scheme for a brushless DC motor", IEEE TRANSACTIONS ON POWER ELECTRON., VOL. 29, NO. 12, pp. 6581-6592, Dec. 2014

[5] Hung-Chi Chen, Hung-He Huang, "Design of buck-type current source inverter fed brushless DC motor drive and its application to position sensorless control with squarewave current" IET Electr. Power Appl., Vol. 7, Iss. 5, pp. 416-426, 2013

[6] Austin Hughes, Electric Motors and Drives, Elseveir 2006

[7] BYOUNG-KUK LEE \& MEHRDAD EHSANI, "Advanced Simulation Model for Brushless DC Motor Drives”, Electric Power Components and Systems, 2003

[8] A.H. Al-Badi, A. Gastli, "MATLAB and PSPICE Dynamic Model of Axial-Field Permanent-Magnet Motor", Science and Technology, 7 (2002), pg.109-121 